\title{
Factors influencing ranchers' intentions to manage for vegetation heterogeneity and promote cross-boundary management in the northern Great Plains
}

\author{
Maggi S. Sliwinski ${ }^{1,2}$, Mark E. Burbach $^{3}$, Larkin A. Powell $^{1}$ and Walter H. Schacht ${ }^{4}$
}

\begin{abstract}
Most private grasslands in the Great Plains are managed with the goal to optimize beef production, which tends to homogenize rangeland habitats. The subsequent loss of vegetation heterogeneity on private lands is detrimental to ecosystem function. However, conservation planners should understand the factors that lead to variation in management of rangelands. We used a mail survey targeted to ranchers in counties with intact rangeland in North Dakota, South Dakota, and Nebraska in 2016 to examine factors predicted to be related to attitudes about strategies leading to heterogeneity such as innovativeness and low risk aversion, and intended behaviors associated with creation of heterogeneity. We used survey questions and a set of relevant scales to examine predictors of behavioral intentions for rangeland management and conservation. Attitudes about fire and prairie dogs, two strategies that create heterogeneity, were largely negative, and ranchers with positive attitudes about fire and prairie dogs and higher perceived behavioral control of their ranch and surrounding landscapes had greater intention to engage in heterogeneity-promoting behaviors. Social norms were also important in predicting intended behaviors and attitudes. Our research suggests that heterogeneity of grasslands may remain low unless land managers understand the importance of spatial and temporal heterogeneity and recognize prescribed fire and prairie dogs, and other burrowing colonial mammals, as principal drivers of ecological processes on rangelands. Conservation organizations may find success by modeling management tools, reducing the perceived effort producers must make to adopt behaviors that support heterogeneity, and by developing programs that work to change social norms around fire and prairie dogs.
\end{abstract}

Key Words: heterogeneity; northern Great Plains; prairie dogs; prescribed fire; rangelands; private lands conservation; wildlife habitat

\section{INTRODUCTION}

Improved livestock distribution and grazing efficiency across the Northern Great Plains have led to structurally homogenous rangelands that greatly limit rangeland plant and animal biodiversity (Toombs et al. 2010, Becerra et al. 2013) and threatens ecosystem services and resilience (Hovick et al. 2014, McGranahan et al. 2018). Some range scientists are calling for a shift to managing rangeland ecosystems for structural heterogeneity and biodiversity at larger scales, rather than managing for grazing distribution at smaller scales; Fuhlendorf et al. (2012) and Freese et al. (2014) suggest that range beef cattle production is compatible with this shift.

Even though there are still relatively large areas of mixed-grass prairie, these areas may not be capable of supporting historic levels of biodiversity because grassland management objectives on privately owned land do not include vegetation heterogeneity (With et al. 2008). Typical management focuses on optimizing beef production (Ortega-S. et al. 2013, Sliwinski et al. 2018) by promoting preferred forage species and increasing the efficiency of the grazing process (Vallentine 2001). Additionally, fire and burrowing mammals such as prairie dogs have been reduced in an effort to maximize rangeland beef production (Freese et al. 2010, Augustine and Derner 2012, Fuhlendorf et al. 2012). These management decisions homogenize the landscape, thus decreasing the habitat types available for different wildlife species (Fuhlendorf and Engle 2001).
Not only is the landscape more homogenous now than in the past, management decisions are generally made within the boundaries of a single, privately owned property, rather than across boundaries at larger scales relevant to wildlife (Ortega-S. et al. 2013). Many wildlife species require large landscapes, and it is unreasonable to assume that individual landowners can influence the trajectory of a wild population. This is a concern for biodiversity conservation because some wildlife species may disappear as patches of similar habitat become smaller than their minimum-area requirements (Noss 1983, Davis 2004). Thus, increasing heterogeneity at larger scales through cross-boundary management, e.g., cooperation among neighbors to use fire as a management tool, to achieve biodiversity conservation requires an understanding of the attitudes land managers have about both heterogeneity and cross-boundary management. Thus, the first objective of this research was to examine ranchers' attitudes about management across boundaries and strategies that have been suggested for creating vegetation heterogeneity, and to determine the factors that influence these attitudes. A second objective of this research was to determine which factors predicted behavioral intentions related to vegetation heterogeneity and cross-boundary management. To do this, we examined the relationship of behavioral intent to attitudes, social norms, and perceived behavioral control using the theory of planned behavior (TPB; Ajzen and Fishbein 1970). The TPB is widely used to explain social and environmental behaviors (Fishbein and Ajzen 2010), and posits that attitudes about the behavior, norms related to the

${ }^{1}$ School of Natural Resources, University of Nebraska-Lincoln, ${ }^{2}$ current affiliation: Grasslands National Park, Parks Canada Agency, ${ }^{3}$ Conservation and Survey Division, School of Natural Resources, University of Nebraska-Lincoln, ${ }^{4}$ Department of Agronomy and Horticulture, University of Nebraska-Lincoln 
behavior, and perceived behavioral control will influence behavioral intent (Ajzen 1991).

\section{METHODS}

\section{Variables and measures}

We were interested in ranchers' attitudes about cross-boundary management because cross-boundary management is important for creating habitat at scales relevant to wildlife populations. We were also interested in ranchers' attitudes about strategies to create vegetation heterogeneity because heterogeneity supports rangeland biodiversity. Below are the variables that we measured with our survey instrument. The first several variables were developed in relation to heterogeneity and cross-boundary management and included attitudes about heterogeneity management, cross-boundary management, temporal vision, and behavioral intent. The last several variables we developed were meant to gauge various characteristics of individuals in general and used as explanatory variables in the models we developed. These variables included endangered species values, perceived behavioral control, land use values, innovativeness (social innovativeness, exploratory acquisition of products, and exploratory information seeking), individualism/collectivism, social norms, and risk aversion. Each of these variables had an associated scale with multiple items, as described below. Participants were asked to rate each item on a Likert scale of 15 , where 1 was strongly disagree and 5 was strongly agree.

\section{Heterogeneity strategies attitudes}

Heterogeneity can be a difficult concept to communicate to a general audience. Because we did not believe many producers would have an attitude about heterogeneity itself, we instead chose to assess attitudes about strategies that can create heterogeneity in intact grassland landscapes. The word "heterogeneity" was not used in our survey sent to producers because the management strategies that lead to heterogeneity in practice are likely more important than a direct attitude about heterogeneity. Thus, we developed a scale based on 8 of the 10 strategies proposed by Freese et al. (2014) for managing for heterogeneity. Strategies included (1) composition and productivity of plant communities, (2) grazing patterns, (3) fire regimes, (4) habitat contiguity, (5) stream hydrology, (6) herbivorous mammal communities, (7) fate of ungulate production, and (8) predators. Multiple items were developed to assess attitudes about each of the eight strategies. The scale was then reviewed by rangeland experts to assess face validity, and a modified Q-sort (Hoffman 2013) was used to test the construct validity of each item, which resulted in 20 items in the scale (Table 1).

\section{Cross-boundary management and temporal vision}

Attitudes about cross-boundary management and temporal vision were assessed using scales developed by Rickenbach et al. (1998). Cross-boundary management attitudes referred to whether landowners believed their property fits into the larger ecosystem; an example item was "My land is part of a much bigger natural system." Temporal vision referred to whether landowners believed their property should be managed for future use; an example item was "What I do on my land will not matter in the long run." Cross-boundary management was considered separate from heterogeneity in the survey because they are separate concepts that are both important for biodiversity.

\section{Behavioral intent}

To assess behavioral intentions using TPB, we developed a scale that asked participants about management across boundaries (four items) and management that could promote vegetation heterogeneity (four items; Table 2). Although these were developed as two subscales, reliability was greater when the subscales were merged into a single scale ( $\alpha=0.75$; Table 3$)$. Participants were asked to indicate how likely they were to engage in the behavior on a 5-point Likert scale.

\section{Endangered species values}

To determine if participants valued threatened and endangered species, we included two items from the within-property scale of Rickenbach et al. (1998). These items included "I would be pleased if a rare or threatened species was found on my land" and "rare or threatened species should be protected."

\section{Perceived behavioral control}

Perceived behavioral control was included as a predictor variable to be used in TPB because previous research showed that it was an important predictor of farmers' intention to adopt best management practices (Borges et al. 2014). To assess perceived behavioral control, we developed a six-item scale with two subscales: one reflected perceived control over ranch management and the other reflected whether managers believed their management affected the larger ecosystem. An example item was "I am able to manage my land to achieve desired outcomes." The construct validity of these items was assessed using the same Qsort method described above prior to survey implementation. After data collection, we merged the two subscales into a single scale for improved reliability.

\section{Land use values}

We used the land use values scale (Sweikert 2017) to assess the relationship that the participants had with their land. This scale was developed specifically for use in agricultural communities and can predict ranchers' attitudes related to conservation (Sweikert 2017). The final land use values scale had 13 items in two domains: human centric (6 items) and nature centric ( 7 items). These domains were used to categorize each participant into one of four domains: eco-social (ranked high in both human and nature domains), naturistic (ranked high only in nature domain), humanistic (ranked high only in human domain), or disconnected (ranked low in both domains). An example item in the humancentric scale was "Farmers and ranchers are masters of the land," and an example in the nature-centric scale was "Farmers and ranchers are only temporary trustees of the land, it is their responsibility to take care of it for future generations."

\section{Innovativeness}

We were interested in participants' innovativeness because of its relevance to adoption of conservation practices (Pannell et al. 2006). In this survey, innovativeness was important to measure because we were asking participants about their willingness to engage in strategies that were new or unfamiliar to them. To measure participant innovativeness we used the exploratory information seeking scale, exploratory acquisition of products scale (Baumgartner and Steenkamp 1996), and the social innovativeness scale (Roehrich 1994 as cited in Roehrich 2004), each with three items. Exploratory information seeking is the search for information on various topics or products and may not 
Table 1. Scale developed following Freese et al. (2014) to measure attitudes toward strategies for increasing vegetation heterogeneity. Constructs or management strategies are in the first column, items associated with each construct are in the second column. Participants were asked to rate how much they agreed with each statement on a 5-point Likert scale. Numbered items were included in the final data analyses. A dagger $\left(^{\dagger}\right)$ indicates a reverse-coded item.

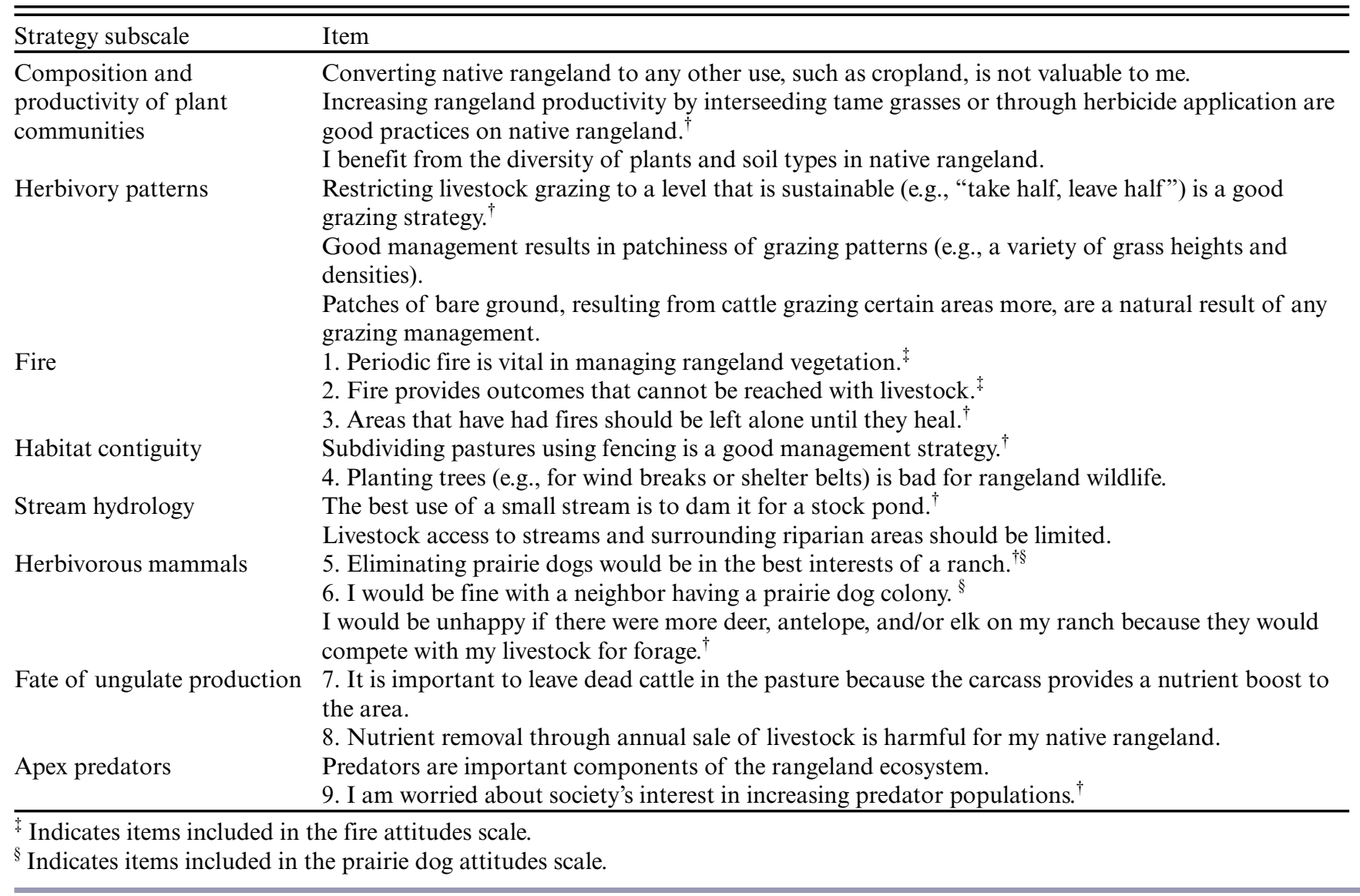

Table 2. Items included in the behavioral intent scale. Participants were asked to indicate how likely they were to engage in the behavior on a 5-point Likert scale.

Alter management to provide habitat for threatened or endangered species.

Work with a neighbor on invasive species control.

Temporarily overgraze some of my pastures to create wildlife habitat.

Work with a neighbor on brush encroachment control.

Manage the threat of wildfires by using prescribed fires.

Change management practices to increase carbon

sequestration on my ranch.

Be prepared for adverse weather such as droughts.

Modify management to increase wildlife populations on my ranch.

be directed at a single topic or product. Exploratory acquisition of products is the acquisition of a product without full knowledge of its potential usefulness. Social innovativeness is associated with the need for uniqueness. We removed one item from the exploratory information seeking scale to improve reliability.

\section{Individualism and collectivism}

Because of the growing interest in promoting cross-boundary management through groups of ranchers (Schutz 2010, Powell 2012), we assessed individualism and collectivism of the participants using a reduced version of a scale that measures horizontal and vertical individualism and collectivism (Sivadas et al. 2008). The horizontal dimension emphasized equality, whereas the vertical dimension emphasized hierarchy. We included two items for each of the four domains, e.g., horizontal individualism, and subsequently collapsed the four domains into an individualism scale and a collectivism scale, each with four items.

\section{Social norms}

Norms are "feelings of moral obligation to perform or refrain from specific actions" (Schwartz and Howard 1981:191). Social norms are important in the decision-making process of ranchers (Yung and Belsky 2007, Sliwinski et al. 2018) and are influential in determining prosocial behavior (Steg and de Groot 2010) such as considering ecosystem services in management decisions. Thus, 
Ecology and Society 23(4): 45 
we developed a scale of five items to assess how much participants agreed with social norms related to rangeland management. An example item in this scale was "Most ranchers in my community act in the best interests of the rangeland." Because of space limitations in the survey, we did not examine the different types of norms, e.g., injunctive versus descriptive.

\section{Risk aversion}

We assumed an assessment of risk aversion was important to include on our survey because the management practices we asked about in the survey, like prescribed fire or working with neighbors on invasive species control, are not yet widely accepted by ranchers. Risk aversion is thought to have an impact on how likely a person is to use a new practice, and has been used in studies of agricultural communities (Ervin and Ervin 1982). We included a risk aversion scale developed by Rohrmann (1997, http://www. rohrmannresearch.net/pdfs/rohrmann-rac-roq.pdf).

\section{Implementation procedures and timeline}

Prior to implementation, the survey was pilot tested by eight individuals working in the ranching industry, and comments were solicited from the Bureau of Sociological Research and the Nebraska Evaluation and Research Center at University of Nebraska-Lincoln. The Nebraska Institutional Review Board reviewed and approved this project prior to implementation.

Surveys were mailed to landowners in eight Nebraska counties (n $=846)$, eleven South Dakota counties $(\mathrm{n}=1096)$, and eight North Dakota counties $(n=931)$. Counties surveyed were in the western parts of these states, where land cover is mostly native rangeland according to recent land cover maps; all counties but one were west of the Missouri River (Fig. 1). In Nebraska, the mailing list was secured through the Nebraska Information Technology Council. Mailing lists for North and South Dakota were purchased from InfoGroup USA. All mailing lists were augmented with lists secured through county assessors. Only addresses for landowners with 1000 acres of land or more were included in the mailing lists, with the assumption that this would result in a list that was primarily ranchers, rather than crop or hobby farmers.

We followed a modified Dillman et al. (2009) approach for mailing surveys. We sent a prenotice postcard on 5 February 2016, a survey mailing with cover letter on 11 February 2016, a follow-up reminder postcard on 17 February 2016, and a replacement survey with a modified cover letter on 11 March 2016 only to those who had not yet returned the survey. To improve response rates, we secured endorsements from a number of organizations known to ranchers, including the Nebraska Cattlemen Association, the North Dakota Grazing Lands Coalition, and the Sandhills Task Force and included these in the second cover letter. We compared our data on age, sex, income from farm, and education to the United States Department of Agriculture (USDA 2015) 2012 Census of Agriculture cattle industry and the United States Census (U.S. Census Bureau 2016) to assess possible nonresponse bias (Dillman et al. 2009).

\section{Data analysis}

Pearson's correlation coefficients among the final variables were calculated (Table 3). Reliability of each scale was assessed using Cronbach's alpha after the data were collected from participants.
Overall, the reliability of the scale for attitudes toward heterogeneity strategies was low $(\alpha=0.63$; Table 3$)$, and reliability of some of the subscales was even lower, e.g., reliability of the scale measuring "composition and productivity of plant communities" was 0.32 . Therefore, we used only the fire attitude and prairie dog attitude subscales (Table 1) instead of the full scale for attitudes toward heterogeneity strategies because these attitudes were shown to be important in a previous study we completed that qualitatively assessed producers' perceptions of heterogeneity (Sliwinski et al. 2018). Fire is a significant ecological process (Fuhlendorf et al. 2012, Powell et al. 2018) and prairie dogs are a keystone species that supports numerous other species (Smith and Lomolino 2004, Davidson et al. 2012); both are principal contributors to heterogeneity that have been largely removed from the northern Great Plains. Inferences that we draw about attitudes toward heterogeneity are therefore made in the context of the choice of these scales.

To meet the first objective of this study, we assessed the relationship between four attitudes (cross-boundary management, temporal vision, fire, and prairie dogs) and the personal characteristics measured, e.g., land use values, risk aversion, etc. We included age and education to assess their influence on attitudes. Structural equation modeling was used to conduct the analysis using latent variables, which allows the structural equation model (SEM) to account for error in the measurement of the variables (Asah 2008, de Leeuw et al. 2015).

To meet the second objective of this study, we examined whether social norms, perceived behavioral control, and attitudes about the behaviors predicted behavioral intent related to landscape vegetation heterogeneity. We only included variables that were significant predictors of the attitudes in the first objective for predicting behavioral intentions in the second objective. Finally, to simplify interpretation, the model was reduced by removing insignificant variables from the full TPB SEM (Toledo et al. 2013). The fit of the SEMs was assessed using the root mean square error of approximation (MacCallum et al. 1996).

\section{RESULTS}

Of 2873 surveys sent, 595 usable surveys were returned for a response rate of $21 \%$. Mean age of participants was 63 years, while mean age of operators from the Census was 58.6 years (USDA 2015). Most of the respondents were male $(86 \%)$, compared to $89 \%$ male primary operators on beef cattle operations in the United States (USDA 2015). Income from on the farm was higher among participants than across the beef industry: $14.4 \%$ of participants reported that $100 \%$ of income came from on the farm, whereas only $3 \%$ reported the same on the Census of Agriculture. The mean number of rangeland acres managed by participants was 6623 acres (range: 70-100000; SD $=9773$; median $=3817$ acres). In our sample, $69 \%$ of participants had at least some college education, whereas $60 \%$ of the general U.S. population had at least some college education.

Most of the scales had reliability $>0.70$; reliability was lower for five scales: individualism ( $\alpha=0.55)$, collectivism $(\alpha=0.60)$, risk aversion $(\alpha=0.59)$, and prairie dog attitudes $(\alpha=0.62$; Table 3$)$.

Attitudes about cross-boundary management were high $(M=$ $4.03, S D=0.62$ ) and were related to perceived behavioral control, land use values, education, and age (Table 4). Participants with 
Fig. 1. The study region included western portions of Nebraska, South Dakota, and North Dakota. Counties that were included in the survey sample are labeled. The lightest gray color indicates rangelands.

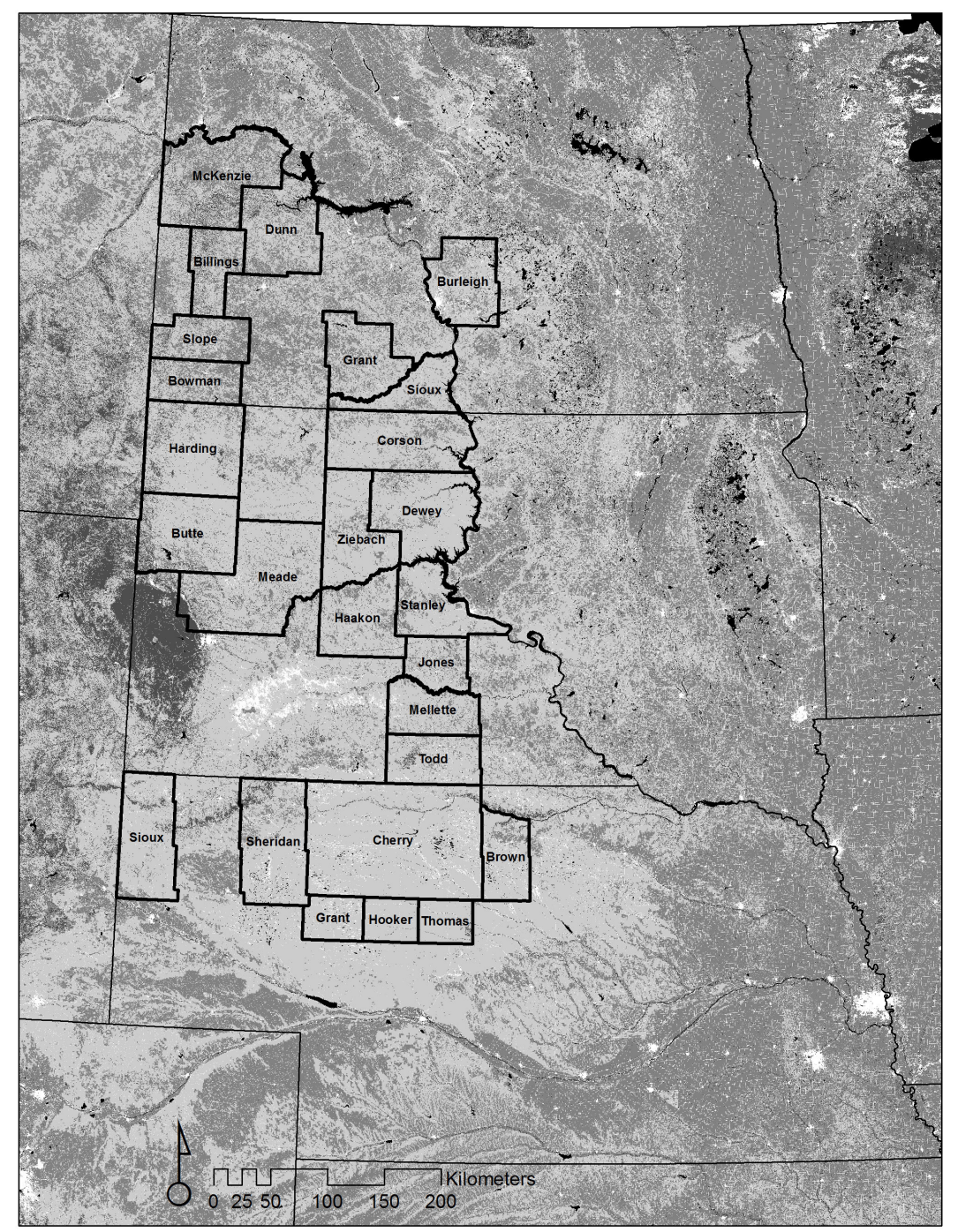

higher perceived behavioral control had more positive attitudes about cross-boundary management. Relative to individuals in the eco-social land use values category, disconnected and humanistic individuals had more negative attitudes and naturistic individuals had more positive attitudes about cross-boundary management. Increased education led to more positive attitudes about crossboundary management, and increased age led to more negative attitudes about cross-boundary management, but crossboundary management attitudes were positive overall (Table 3).

Temporal vision was high $(M=4.43, S D=0.58)$ and was significantly related to social norms, perceived behavioral control, land use values, and age (Table 4). Participants that agreed with social norms and with greater perceived behavioral control had more positive attitudes about temporal vision; as age increased, attitudes about temporal vision became more negative. Disconnected and humanistic individuals had more negative attitudes and naturistic individuals had more positive attitudes about temporal vision compared to individuals in the eco-social land use values category.

Attitudes about fire were low $(M=2.51, S D=1.10)$, and only values about threatened and endangered species and exploratory acquisition of products were correlated to fire attitudes; both were positively related to fire attitudes (Table 4). Prairie dog attitudes were low $(M=1.63, S D=0.87)$ and were explained by values about threatened and endangered species, social norms, exploratory information seeking, and land use values (Table 4). Values about threatened and endangered species were correlated with attitudes about prairie dogs; negative attitudes about prairie dogs were associated with social norms and exploratory information seeking behavior. Finally, individuals in the naturistic land use value category had more positive attitudes about prairie dogs than the other categories. 
Table 4. Parameter estimates $(\beta)$, standard errors (SE), and p-values for four attitudes related to cross-boundary attitudes, temporal vision, fire, and prairie dogs in rangeland ecosystems and the variables that were hypothesized to explain them. Bold text indicates a significant relationship at $\mathrm{p}<0.05$. Analysis was completed using structural equation modeling. Abbreviations: $\mathrm{T}+\mathrm{E}=$ threatened and endangered; EAP = exploratory acquisition of products; EIS = exploratory information seeking; LUV = land use values scale.

\begin{tabular}{|c|c|c|c|c|c|c|c|c|c|c|c|c|}
\hline \multirow[b]{2}{*}{ Variable } & \multicolumn{3}{|c|}{$\begin{array}{c}\text { Cross-boundary } \\
\text { attitudes }\end{array}$} & \multicolumn{3}{|c|}{$\begin{array}{c}\text { Temporal vision } \\
\text { attitudes }\end{array}$} & \multicolumn{3}{|c|}{$\begin{array}{c}\text { Fire } \\
\text { attitudes }\end{array}$} & \multicolumn{3}{|c|}{ Prairie dog attitudes } \\
\hline & $\beta$ & SE & $p$ & $\beta$ & SE & $p$ & $\beta$ & SE & $p$ & $\beta$ & SE & $p$ \\
\hline $\mathrm{T}+\mathrm{E}$ species & -0.02 & 0.04 & 0.57 & -0.01 & 0.03 & 0.85 & 0.37 & 0.09 & $<0.01$ & 0.33 & 0.06 & $<0.01$ \\
\hline Social norms & 0.05 & 0.08 & 0.53 & 0.13 & 0.05 & 0.02 & -0.07 & 0.15 & 0.66 & -0.25 & 0.11 & 0.02 \\
\hline Perceived control & 0.77 & 0.10 & $<0.01$ & 0.49 & 0.08 & $<0.01$ & 0.27 & 0.17 & 0.12 & 0.06 & 0.12 & 0.62 \\
\hline Social innovativeness & -0.03 & 0.07 & 0.68 & -0.05 & 0.05 & 0.33 & -0.27 & 0.16 & 0.08 & -0.01 & 0.11 & 0.93 \\
\hline EAP & 0.03 & 0.08 & 0.71 & -0.03 & 0.05 & 0.57 & 0.43 & 0.16 & $<0.01$ & 0.18 & 0.11 & 0.10 \\
\hline EIS & -0.00 & 0.04 & 0.93 & 0.03 & 0.03 & 0.30 & 0.09 & 0.08 & 0.25 & -0.17 & 0.06 & $<0.01$ \\
\hline Individualism & 0.13 & 0.18 & 0.47 & 0.15 & 0.11 & 0.17 & -0.70 & 0.38 & 0.06 & -0.33 & 0.25 & 0.19 \\
\hline Collectivism & -0.01 & 0.23 & 0.98 & -0.06 & 0.16 & 0.70 & -0.84 & 0.51 & 0.10 & -0.17 & 0.34 & 0.61 \\
\hline Risk aversion & 0.00 & 0.09 & 0.97 & 0.11 & 0.07 & 0.11 & -0.26 & 0.19 & 0.17 & 0.12 & 0.13 & 0.38 \\
\hline LUV “disconnected" & -0.45 & 0.19 & 0.02 & -0.63 & 0.14 & $<0.01$ & 0.10 & 0.37 & 0.79 & 0.25 & 0.28 & 0.37 \\
\hline LUV "humanistic" & -0.60 & 0.21 & $<0.01$ & -0.53 & 0.17 & $<0.01$ & 0.23 & 0.41 & 0.57 & -0.41 & 0.31 & 0.19 \\
\hline LUV "naturistic" & 0.27 & 0.05 & $<0.01$ & 0.11 & 0.04 & $<0.01$ & 0.04 & 0.10 & 0.67 & 0.25 & 0.07 & $<0.01$ \\
\hline Education: high school & 0.53 & 0.20 & 0.01 & 0.18 & 0.14 & 0.18 & -0.23 & 0.38 & 0.54 & 0.30 & 0.30 & 0.33 \\
\hline Education: some college & 0.64 & 0.20 & $<0.01$ & 0.12 & 0.14 & 0.36 & -0.08 & 0.38 & 0.83 & 0.44 & 0.31 & 0.15 \\
\hline Education: Associate's & 0.59 & 0.22 & 0.01 & 0.09 & 0.14 & 0.54 & -0.07 & 0.41 & 0.86 & 0.24 & 0.33 & 0.47 \\
\hline Education: Bachelor's & 0.64 & 0.20 & $<0.01$ & 0.19 & 0.14 & 0.16 & 0.09 & 0.38 & 0.82 & 0.40 & 0.31 & 0.19 \\
\hline Education: advanced & 0.74 & 0.21 & $<0.01$ & 0.05 & 0.14 & 0.71 & 0.26 & 0.40 & 0.51 & 0.45 & 0.32 & 0.16 \\
\hline Age & -0.01 & 0.00 & 0.02 & -0.01 & 0.00 & $<0.01$ & 0.00 & 0.01 & 0.71 & 0.00 & 0.00 & 0.63 \\
\hline
\end{tabular}

Participants had neutral intent to engage in behaviors that promote cross-boundary management and heterogeneity $(M=$ $2.95, S D=0.67$ ); behavioral intent was predicted most strongly by attitudes about prairie dogs, attitudes about fire, and perceived behavioral control (Table 5, Fig. 2). Social norms were predictive of prairie dog attitudes $(\beta=-0.26)$ but not behavioral intent. All the variables that were significant predictors of the attitudes about fire and prairie dogs from the first objective remained significant in the final SEM. Both fire and prairie dog attitudes were positively related to behavioral intent $(\beta=0.15,0.25$ respectively). Perceived behavioral control was the strongest predictor of behavioral intent $(\beta=0.58)$.

\section{DISCUSSION}

\section{General results}

Our response rates were low but not unusual for recent surveys of agricultural populations in the U.S. (e.g., Chouinard et al. 2008, Quinn and Burbach 2010, Sheeder and Lynne 2011). Our sample was very similar to U.S. Agricultural Census Data for the cattle industry, except for differences caused by our selection of producers with at least 1000 acres of land. A higher percent of sample with $100 \%$ ranch-only income (14\% vs. $3 \%$ nationally) likely resulted from our sample inclusion of two of the highest producing beef states (Nebraska and South Dakota), and two of the highest producing beef counties (Cherry, NE and Meade, SD). Thus, the risk of nonresponse bias seems low.
Table 5. Theory of planned behavior (TPB) variables that predicted engagement in behaviors that contribute to landscape and heterogeneity management and their coefficient estimates $(\beta)$, standard errors (SE), and p-values for participants from Nebraska, South Dakota, and North Dakota in 2016. T+E = threatened and endangered; LUV $=$ land use values scale.

\begin{tabular}{lccc}
\hline \hline Regressions: & $\begin{array}{c}\text { Esti- } \\
\text { mate }\end{array}$ & SE & $\begin{array}{c}p \text { - } \\
\text { value }\end{array}$ \\
\hline Behavioral intent & & & \\
Fire attitudes & 0.15 & 0.04 & $<0.01$ \\
Prairie dog attitudes & 0.25 & 0.06 & $<0.01$ \\
Norms & 0.08 & 0.07 & 0.26 \\
Perceived behavioral control & 0.58 & 0.09 & $<0.01$ \\
& & & \\
Fire attitudes & & & \\
Threatened and endangered species & 0.37 & 0.06 & $<0.01$ \\
Exploratory acquisition of products & 0.31 & 0.09 & $<0.01$ \\
& & & \\
Prairie dog attitudes & & & \\
T+E Species & 0.37 & 0.05 & $<0.01$ \\
Norms & -0.26 & 0.07 & $<0.01$ \\
Exploratory information seeking & -0.21 & 0.06 & $<0.01$ \\
LUV disconnected & 0.34 & 0.30 & 0.25 \\
LUV humanistic & -0.17 & 0.32 & 0.59 \\
LUV naturistic & 0.26 & 0.07 & $<0.01$ \\
\hline
\end{tabular}


Fig. 2. Theory of planned behavior (TPB) variables that predicted intention to behave in ways that contribute to landscape and heterogeneity management for participants in Nebraska, South Dakota, and North Dakota in 2016. Solid lines indicate significant relationships, dotted line indicates nonsignificant relationship. Values above lines are coefficients. Circles indicate that the variable is latent. The middle and right-hand side of the diagram is the original TPB, where attitudes, perceived behavioral control, and social norms predict behavioral intentions. The left-hand side of the diagram is a recent extension of TPB, which uses other variables to predict attitudes. Abbreviations: LUV = land use values; EIS = exploratory information seeking; $\mathrm{T}+\mathrm{E}$ species $=$ threatened and endangered species; EAP = exploratory acquisition of products; $\mathrm{PBC}=$ perceived behavioral control.

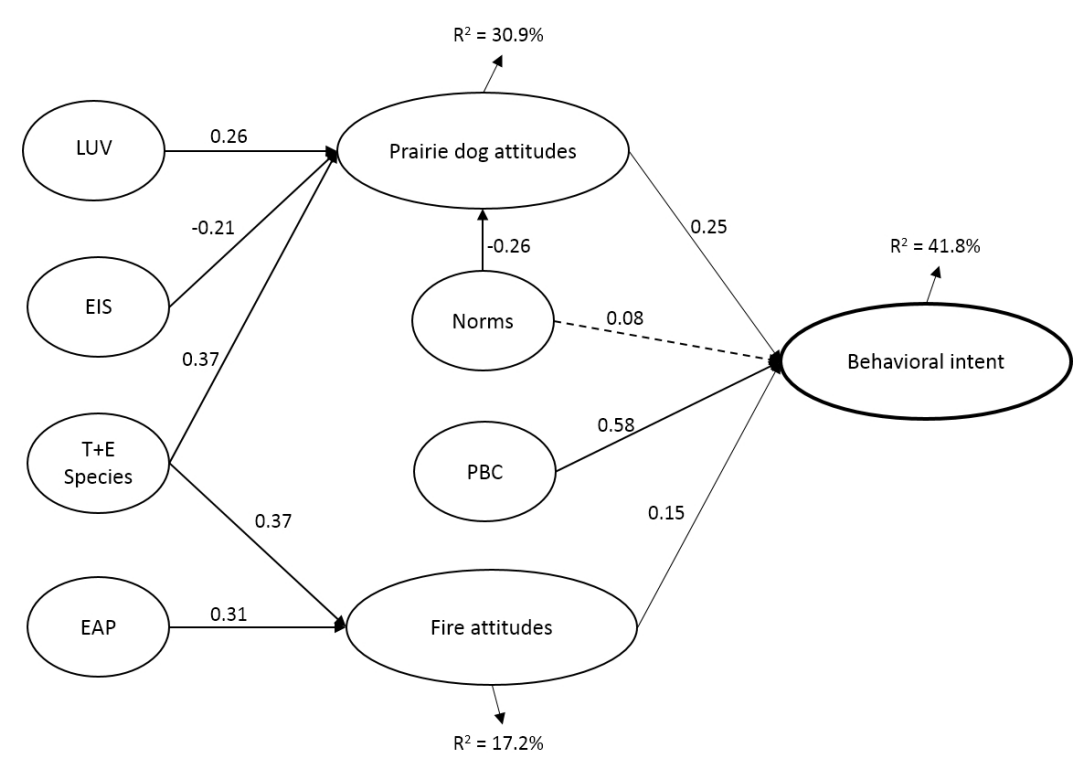

Participants' attitudes toward cross-boundary management and their temporal vision were generally positive, which confirmed that ranchers realize they are not isolated spatially or temporally, and that their management practices affect neighboring lands as well as the future health of the land. This agrees with previous research that suggested ranchers consider themselves stewards of the land (Gutwein and Goldstein 2013, Kennedy et al. 2016). Attitudes about threatened and endangered species in our survey, however, were relatively negative. The Endangered Species Act is often feared by private landowners (Liffmann et al. 2000), in part because it represents a coercive technique that the federal government uses to regulate management on private lands; thereby, landowners lose control of management of their land (Knapp et al. 2015).

Participant attitudes about fire and prairie dogs (as proxies for attitudes related to heterogeneity) were generally negative. This was somewhat surprising given recent studies showing greater use of prescribed fires across the Great Plains (Twidwell et al. 2013). Previous work examining ranchers' attitudes about visual characteristics of the landscape indicated that ranchers tended to value homogeneity, which they considered best for beef production and which leads to the "management to the middle" phenomenon (Becerra et al. 2013, Fuhlendorf et al. 2006, Sliwinski et al. 2018). Management to the middle describes the reduction of heterogeneity in vegetation structure that can occur with grazing management that optimizes beef production. This phenomenon is considered to be one cause of declining grassland biodiversity in the Great Plains (Fuhlendorf et al. 2006).

The result that the scale measuring attitudes toward heterogeneity strategies as originally developed did not have high reliability is likely related to the complexity of the concept of heterogeneity itself and the framework on which we based scale development (i.e., Freese et al. 2014). Participants could easily hold positive attitudes about some aspects of heterogeneity and negative attitudes about others, without relating the attitudes directly to heterogeneity. For instance, most ranchers reported that converting rangeland to cropland was not good for their operation, most likely not because it resulted in a decline in heterogeneity and wildlife habitat but because their rangeland could not support crops or they did not wish to farm. In other cases, the significance of some indicators of heterogeneity identified by Freese et al. (2014) that were used as the basis for some of our survey questions might not have been apparent to the ranchers. For example, the significance of one of our survey questions "Nutrient removal through annual sale of livestock is harmful for my native rangeland" may not have been readily interpretable. For these reasons, we recommend that future research designed to assess heterogeneity attitudes focus on 
specific characteristics of heterogeneity, e.g., spatial distribution of bare ground and/or rested areas, or specific tools to increase heterogeneity, e.g., grass banking or fire, that are easily defined for the participants and thus accurately studied.

\section{Predicting attitudes}

An important predictor of attitudes about prairie dogs was social norms. Social norms are often very important to agricultural communities, and can limit ranchers' willingness to engage in new practices (Didier and Brunson 2004, Knapp and FernandezGimenez 2009). A recent study showed that most ranchers value homogeneity over heterogeneity (Becerra et al. 2017), which may be related to social norms that prevent individual ranchers from valuing heterogeneity. Although our study did not examine the different types of social norms, research in real-life contexts has identified injunctive normative messages as more effective at promoting desired attitudes than descriptive norms (Schultz et al. 2007). Injunctive normative messages provide an indication of social approval or disapproval, whereas descriptive normative messages provide detailed information about the general behavior of others.

Another predictor of attitudes about prairie dogs was exploratory information-seeking behavior, wherein participants who were higher on this scale also had more negative attitudes toward prairie dogs. Liffmann et al. (2000) reported that ranchers usually relied on information from other ranchers and cattlemen's associations, which are information sources that may reinforce negative attitudes about prairie dogs (e.g., Rapid City Journal 2012). Extension educators are often trusted by the ranching community (Liffmann et al. 2000), and may be able to foster dialogue between ranching communities and scientists.

When a participant valued threatened and endangered species, attitudes about both fire and prairie dogs were more positive. A better understanding of endangered species may lead to greater willingness to participate in conservation efforts (Henderson et al. 2014). Tying information about threatened, endangered, and candidate species into educational programming done by extension services may help to alleviate some fears of the Endangered Species Act, as may efforts to work with local partners on threatened and endangered species conservation (Brown et al. 2010, Knapp et al. 2015).

\section{Predicting intended behaviors}

Our results highlight the importance of social norms and attitudes about prairie dogs and fire because they influence intended behaviors that promote vegetation heterogeneity and crossboundary management. Previous research has shown that ranchers value homogeneity over heterogeneity (Becerra et al. 2017), and few participants in our study had positive attitudes about fire and prairie dogs, two ecosystem drivers that can create heterogeneity. Thus, it may be important to focus on social norms and attitudes about fire and prairie dogs to increase potential for vegetation heterogeneity across landscapes in the Great Plains. Attitudes about cross-boundary management and temporal vision were not significant predictors of behavioral intent, and these attitudes were generally very positive.

Perceived behavioral control was an important factor in predicting behavioral intentions; thus, programs that can reduce the effort needed to implement new behaviors may prove useful.
Our survey did not address perceived behavioral control regarding fire and prairie dogs directly, but factors related to control and norms may influence attitudes toward prescribed fire (Toledo et al. 2013), thus further research to examine these topics would be valuable.

\section{Influencing behavior}

Our study showed that ranchers in the northern Great Plains have positive attitudes about working with their neighbors to solve problems, which may provide potential for conservation planners to influence behavior. But, we speculate that the approach used will be critical. Three broad strategies are used for influencing behavior: education, positive motivation, and coercion (De Young 1993). For education to be successful, it will be important for the information to come from trusted sources, otherwise it may be ignored (Sliwinski et al. 2018). University extension activities have been successful at influencing behavior (Richards and George 1996), most likely because they are hands-on activities (Heberlein 2012). However, education alone is unlikely to directly influence behavior (Heberlein 2012). Coercive techniques include regulation, which can restrict or penalize certain behaviors (Serbruyns and Luyssaert 2006). Coercive strategies may be counterproductive: ranchers in northwestern Colorado planned to withdraw from conservation activities if a species was listed as endangered (Knapp et al. 2015) and many of our participants did not value threatened and endangered species, suggesting that coercive strategies are not conducive to conservation. Positive motivational techniques are used in incentive programs (Pascual and Perrings 2007); for example, the voluntary Conservation Reserve Program pays landowners to take fragile land out of crop production and plant it to perennial cover (Reimer and Prokopy 2014). Positive motivational techniques may overcome negative norms around fire and prairie dog management, but this strategy does not work to change the norms themselves.

Conservation campaigns that rely on the power of social norms to influence behavior (Schultz et al. 2007) might benefit from engaging locally respected individuals such as extension educators or others within ranchers' professional and personal networks. Social norms reinforce traditional, accepted agricultural management activities (Baumgart-Getz et al. 2012, Marchini and Macdonald 2012); in the northern Great Plains, this results in relative homogeneity of grasslands. Further research to examine norms specific to the context of fire (e.g., Toledo et al. 2013), grass banking, and herbivorous mammals such as prairie dogs would improve the development of strategies for influencing norms and therefore behavior.

\section{IMPLICATIONS}

Private individuals own and manage much of the native rangelands in the Great Plains (Askins et al. 2007), and they are being encouraged by conservationists to shift to a paradigm that fosters cross-boundary management and vegetation heterogeneity as a means of improving wildlife habitat on rangelands. However, social norms are important to the fabric of ranching communities and are difficult to change (Willcox et al. 2012, Sliwinski et al. 2018). Adherence to social norms and attitudes about threatened and endangered species were important predictors of attitudes about prairie dogs and fire, thus programs to influence social norms around these topics are means of increasing conservation outcomes. Disseminating research results that demonstrate that 
heterogeneity management on grazing lands leads to sustained production (e.g., Augustine and Springer 2013, Scasta et al. 2015) may start shifting the long-held beliefs about depressed livestock production on land managed with fire and/or inhabited by prairie dogs. However, education programs alone will not change behavior (Tanaka et al. 2011, Heberlein 2012). Positive motivational techniques may provide opportunities to engage landowners in species conservation if landowners perceive that the proposed management alternative reduces risk levels, including the threat of future government regulation (Jenny et al. 2004, Trainor et al. 2013), as our research suggests. Our research showed that social norms and perceived control issues related to prescribed fire and prairie dogs will need to be accounted for in new programs that promote vegetation heterogeneity across boundaries. Existing resources such as university ranches and extension could work to increase awareness of conservation programs tailored to the ranching community and to model and teach prescribed fire techniques and alternative management options for prairie dogs.

Responses to this article can be read online at: http://www.ecologyandsociety.org/issues/responses. php/10660

\section{Acknowledgments:}

Funding for this work was provided from USDA Sustainable Agriculture Research and Education North-Central Region [grant number H003679429] and Federal Aid in Wildlife Restoration Project through the Nebraska Game and Parks Commission [grant number W-103-R001]. We are grateful to the producers who completed the survey and to Katie McCollum for entering the survey data.

\section{LITERATURE CITED}

Ajzen, I. 1991. The theory of planned behavior. Organizational Behavior and Human Decision Processes 50:179-211. http://dx. doi.org/10.1016/0749-5978(91)90020-T

Ajzen, I., and M. Fishbein. 1970. The prediction of behavior from attitudinal and normative variables. Journal of Experimental Social Psychology 6:466-487. http://dx.doi.org/10.1016/0022-1031 (70) $90057-0$

Asah, S. T. 2008. Empirical social-ecological system analysis: from theoretical framework to latent variable structural equation model. Environmental Management 42:1077-1090. http://dx.doi. org/10.1007/s00267-008-9172-9

Askins, R. A., F. Chávez-Ramírez, B. C. Dale, C. A. Haas, J. R. Herkert, F. L. Knopf, and P. D. Vickery. 2007. Conservation of grassland birds in North America: understanding ecological processes in different regions. Ornithological Monographs 64:1-46. http://dx.doi.org/10.2307/40166905

Augustine, D. J., and J. D. Derner. 2012. Disturbance regimes and Mountain Plover habitat in shortgrass steppe: large herbivore grazing does not substitute for prairie dog grazing or fire. Journal of Wildlife Management 76:721-728. http://dx.doi.org/10.1002/ jwmg. 334
Augustine, D. J., and T. L. Springer. 2013. Competition and facilitation between a native and a domestic herbivore: trade-offs between forage quantity and quality. Ecological Applications 23:850-863. http://dx.doi.org/10.1890/12-0890.1

Baumgart-Getz, A., L. S. Prokopy, and K. Floress. 2012. Why farmers adopt best management practice in the United States: a meta-analysis of the adoption literature. Journal of Environmental Management 96:17-25. http://dx.doi.org/10.1016/j.jenvman.2011.10.006

Baumgartner, H., and J. B. E. M. Steenkamp. 1996. Exploratory consumer buying behavior: conceptualization and measurement. International Journal of Research in Marketing 13:121-137. http:// dx.doi.org/10.1016/0167-8116(95)00037-2

Becerra, T. A., D. M. Engle, R. D. Elmore, and S. D. Fuhlendorf. 2013. Contrasting preference for grassland landscapes among population groups in the central and southern Great Plains. Rangeland Ecology \& Management 66(5):529-538. http://dx.doi. org/10.2111/REM-D-12-00174.1

Becerra, T. A., D. M. Engle, S. D. Fuhlendorf, and D. Elmore. 2017. Preference for grassland heterogeneity: implications for biodiversity in the Great Plains. Society \& Natural Resources. 30 (5):601-612. http://dx.doi.org/10.1080/08941920.2016.1239293

Borges, J. A. R., A. G. J. M. Oude Lansink, C. M. Ribeiro, and V. Lutke. 2014. Understanding farmers' intention to adopt improved natural grassland using the theory of planned behavior. Livestock Science 169:163-174. http://dx.doi.org/10.1016/j. livsci.2014.09.014

Brown, M. B., M. E. Burbach, J. J. Dinan, R. J. Held, R. J. Johnson, J. G. Jorgensen, J. Lackey, J. F. Marcus, G. S. Matkin, and C. M. Thody. 2010. Nebraska's tern and plover conservation partnership - a model for sustainable conservation of threatened and endangered species. Wader Study Group Bulletin 118:1-4.

Chouinard, H. H., T. Paterson, P. R. Wandschneider, and A. M. Ohler. 2008. Will farmers trade profits for stewardship? Heterogeneous motivations for farm practice selection. Land Economics 84(1):66-82. http://dx.doi.org/10.3368/le.84.1.66

Davidson, A. D., J. K. Detling, J. H. Brown. 2012. Ecological roles and conservation challenges of social, burrowing, herbivorous mammals in the world's grasslands. Frontiers in Ecology and Environment 10:477-486. http://dx.doi.org/10.1890/110054

Davis, S. K. 2004. Area sensitivity in grassland passerines: effects of patch size, patch shape, and vegetation structure on bird abundance and occurrence in southern Saskatchewan. Auk 121:1130-1145. http://dx.doi.org/10.1642/0004-8038(2004)121[1130: ASIGPE]2.0.CO;2

de Leeuw, A., P. Valois, I. Ajzen, and P. Schmidt. 2015. Using the theory of planned behavior to identify key beliefs underlying proenvironmental behavior in high-school students: implications for educational interventions. Journal of Environmental Psychology 42:128-138. http://dx.doi.org/10.1016/j.jenvp.2015.03.005

De Young, R. 1993. Changing behavior and making it stick: the conceptualization and management of conservation behavior. Environment and Behavior 25:485-505. http://dx.doi. org/10.1177/0013916593253003 
Didier, E. A., and M. W. Brunson. 2004. Adoption of range management innovations by Utah ranchers. Journal of Range Management 57:330-336. http://dx.doi.org/10.2307/4003855

Dillman, D. A., J. D. Smyth, and L. M. Christian. 2009. Internet, mail, and mixed-mode surveys: the tailored design method. Third edition. John Wiley \& Sons, Hoboken, New Jersey, USA.

Ervin, C. A., and D. Ervin. 1982. Factors affecting the use of soil conservation practices: hypotheses, evidence, and policy implications. Land Economics 58:277-292. http://dx.doi. org/10.2307/3145937

Fishbein, M., and I. Ajzen. 2010. Predicting and changing behavior: the reasoned action approach. Psychology Press, New York, New York, USA. http://dx.doi.org/10.4324/9780203838020

Freese, C. H., S. D. Fuhlendorf, and K. Kunkel. 2014. A management framework for the transition from livestock production toward biodiversity conservation on Great Plains rangelands. Ecological Restoration 32:358-368. http://dx.doi. org/10.3368/er.32.4.358

Freese, C. H., D. Montanye, and F. D. Fleischman. 2010. Proposed standards and guidelines for private nature reserves in the northern Great Plains. Great Plains Research 20:71-84.

Fuhlendorf, S. D., and D. M. Engle. 2001. Restoring heterogeneity on rangelands: ecosystem management based on evolutionary grazing patterns. BioScience 51:625-632. http://dx.doi. org/10.1641/0006-3568(2001)051[0625:RHOREM]2.0.CO;2

Fuhlendorf, S. D., D. M. Engle, R. D. Elmore, R. F. Limb, and T. G. Bidwell. 2012. Conservation of pattern and process: developing an alternative paradigm of rangeland management. Rangeland Ecology \& Management 65:579-589. http://dx.doi. org/10.2111/REM-D-11-00109.1

Fuhlendorf, S. D., W. C. Harrell, D. M. Engle, R. G. Hamilton, C. A. Davis, and D. M. Leslie, Jr. 2006. Should heterogeneity be the basis for conservation? Grassland bird response to fire and grazing. Ecological Applications 16(5):1706-1716. http://dx.doi. org/10.1890/1051-0761(2006)016[1706:SHBTBF]2.0.CO;2

Gutwein, M., and J. H. Goldstein. 2013. Integrating conservation and financial objectives on private rangelands in northern Colorado: rancher and practitioner perceptions. Rangeland Ecology \& Management 66:330-338. http://dx.doi.org/10.2111/ REM-D-11-00206.1

Heberlein, T. A. 2012. Navigating environmental attitudes. Conservation Biology 26:583-585. http://dx.doi.org/10.1111/ j.1523-1739.2012.01892.x

Henderson, A. E., M. Reed, and S. K. Davis. 2014. Voluntary stewardship and the Canadian Species at Risk Act: exploring rancher willingness to support species at risk in the Canadian prairies. Human Dimensions of Wildlife 19:17-32. http://dx.doi. org/10.1080/10871209.2013.819595

Hoffman, C. M. 2013. Building upon common-pool resource theory to explore success in transitioning water management institutions. Dissertation. University of Nebraska-Lincoln, Lincoln, Nebraska, USA.

Jenny, J. P., W. Heinrich, A. B. Montoya, B. Mutch, C. Sandfort, and W. G. Hunt. 2004. Progress in restoring the Aplomado Falcon to southern Texas. Wildlife Society Bulletin 32(1):276-285. http:// dx.doi.org/10.2193/0091-7648(2004)32[276:FTFPIR]2.0.CO;2

Kennedy, S. M., M. Burbach, and M. S. Sliwinski. 2016. Sustainable grassland management: an exploratory study of progressive ranchers in Nebraska. Sustainable Agriculture Research 5:103. http://dx.doi.org/10.5539/sar.v5n2p103

Knapp, C. N., F. S. Chapin III, and J. O. Cochran. 2015. Ranch owner perceptions and planned actions in response to a proposed Endangered Species Act listing. Rangeland Ecology \& Management 68:453-460. http://dx.doi.org/10.1016/j.rama.2015.08.003

Knapp, C. N., and M. E. Fernandez-Gimenez. 2009. Knowledge in practice: documenting rancher local knowledge in northwest Colorado. Rangeland Ecology \& Management 62:500-509. http:// dx.doi.org/10.2111/08-175.1

Liffmann, R. H., L. Huntsinger, and L. C. Forero. 2000. To ranch or not to ranch: home on the urban range? Journal of Range Management 53:362-370. http://dx.doi.org/10.2307/4003745

MacCallum, R. C., M. W. Browne, and H. M. Sugawara. 1996. Power analysis and determination of sample size for covariance structure modeling. Psychological Methods 1:130-149. http://dx. doi.org/10.1037/1082-989X.1.2.130

Marchini, S., and D. W. Macdonald. 2012. Predicting ranchers' intention to kill jaguars: case studies in Amazonia and Pantanal. Biological Conservation 147:213-221. http://dx.doi.org/10.1016/j. biocon.2012.01.002

McGranahan, D. A., T. J. Hovick., R. D. Elmore, D. M. Engle, and S. D. Fuhlendorf. 2018. Moderate patchiness optimizes heterogeneity, stability, and beta diversity in mesic grassland. Ecology and Evolution 8:5008-5015. http://dx.doi.org/10.1002/ $\underline{\text { ece } 3.4081}$

Noss, R. F. 1983. A regional landscape approach to maintain diversity. BioScience 33(11):700-706. http://dx.doi.org/10.2307/1309350

Ortega-S., J. A., S. D. Lukefahr, and F. C. Bryant. 2013. Optimum stocking rate, monitoring, and flexibility: key components of successful grazing management programs. Rangelands 35 (5):22-27. http://dx. doi.org/10.2111/RANGELANDS-D-13-00021.1

Pannell, D. J., G. R. Marshall, N. Barr, A. Curtis, F. Vanclay, and R. Wilkinson. 2006. Understanding and promoting adoption of conservation practices by rural landholders. Australian Journal of Experimental Agriculture 46:1407-1424. http://dx.doi.org/10.1071/ EA05037

Pascual, U., and C. Perrings. 2007. Developing incentives and economic mechanisms for in situ biodiversity conservation in agricultural landscapes. Agriculture, Ecosystems \& Environment 121:256-268. http://dx.doi.org/10.1016/j.agee.2006.12.025

Powell, J., B. Martin, V. J. Dreitz, and B. W. Allred. 2018. Grazing preferences and vegetation feedbacks of the fire-grazing interaction in the northern Great Plains. Rangeland Ecology \& Management 71:45-52. http://dx.doi.org/10.1016/j.rama.2017.09.003

Powell, L. A. 2012. Common-interest community agreements on private lands provide opportunity and scale for wildlife management. Animal Biodiversity and Conservation 35:295-306. 
Quinn, C. E., and M. E. Burbach. 2010. A test of personal characteristics that influence farmer's pro-environmental behaviors. Great Plains Research 20:193-204.

Rapid City Journal. 2012. South Dakota ranchers seek state action on prairie dogs. 29 January. [online] URL: https:// rapidcityjournal.com/news/south-dakota-ranchers-seek-state-actionon-prairie-dogs/article 990808f4-4aa2-11e1-aa6a-001871e3ce6c. $\underline{\mathrm{html}}$

Reimer, A. P., and L. S. Prokopy. 2014. Farmer participation in U.S. Farm Bill conservation programs. Environmental Management 53:318-332. http://dx.doi.org/10.1007/s00267-013-0184-8

Richards, R. T., and M. R. George. 1996. Evaluating changes in ranch management practices through extension education. Journal of Range Management 49:76-80. http://dx.doi. org/10.2307/4002729

Rickenbach, M. G., D. B. Kittredge, D. M. Dennis, and T. H. Stevens. 1998. Ecosystem management: capturing the concept for woodland owners. Journal of Forestry 96:18-24.

Roehrich, G. 2004. Consumer innovativeness: concepts and measurements. Journal of Business Research 57:671-677. http:// dx.doi.org/10.1016/S0148-2963(02)00311-9

Scasta, J. D., E. T. Thacker, T. J. Hovick, D. M. Engle, B. W. Allred, S. D. Fuhlendorf, J. R. Weir. 2015. Patch-burn grazing (PBG) as a livestock management alternative for fire-prone ecosystems of North America. Renewable Agriculture and Food Systems 31:550-567. http://dx.doi.org/10.1017/S1742170515000411

Schultz, P. W., J. M. Nolan, R. B. Cialdini, N. J. Goldstein, and V. Griskevicius. 2007. The constructive, destructive, and reconstructive power of social norms. Psychological Science 18:429-434. http://dx.doi.org/10.1111/j.1467-9280.2007.01917.x

Schutz, A. B. 2010. Grassland governance and common-interest communities. Sustainability 2:2320-2348. http://dx.doi.org/10.3390/ su2072320

Schwartz, S. H., and J. A. Howard. 1981. A normative decisionmaking model of altruism. Pages 189-211 in J. P. Sorrentino and R. M. Rushton, editors. Altruism and helping behavior. Lawrence Erlbaum, Hillsdale, New Jersey, USA.

Serbruyns, I., and S. Luyssaert. 2006. Acceptance of sticks, carrots and sermons as policy instruments for directing private forest management. Forest Policy and Economics 9:285-296. http://dx.doi.org/10.1016/j.forpol.2005.06.012

Sheeder, R. J., and G. D. Lynne. 2011. Empathy conditioned conservation: "walking-in-the-shoes-of-others" as a conservation farmer. Land Economics 87(3):433-452. http://dx.doi.org/10.3368/ le.87.3.433

Sivadas, E., N. T. Bruvold, and M. R. Nelson. 2008. A reduced version of the horizontal and vertical individualism and collectivism scale: a four-country assessment. Journal of Business Research 61:201-210. http://dx.doi.org/10.1016/j.jbusres.2007.06.016

Sliwinski, M. S., M. Burbach, L. Powell, and W. Schacht. 2018. Ranchers' perceptions of vegetation heterogeneity in the northern Great Plains. Great Plains Research 28(2):185-197. http://dx.doi. org/10.1353/gpr.2018.0029
Smith, G. A., and M. V. Lomolino. 2004. Black-tailed prairie dogs and the structure of avian communities on the shortgrass plains. Oecologia 138:592-602. http://dx.doi.org/10.1007/s00442-003-1465-3

Steg, L., and J. de Groot. 2010. Explaining prosocial intentions: testing causal relationships in the norm activation model. British Journal of Social Psychology 49:725-743. http://dx.doi. org/10.1348/014466609X477745

Sweikert, L. A. 2017. Human dimensions of habitat loss in the plains and prairie potholes ecoregion. Dissertation. South Dakota State University, Brookings, South Dakota, USA.

Tanaka, J. A., M. Brunson, and L. A. Torell. 2011. A social and economic assessment of rangeland conservation practices. Pages 371-422 in D. D. Briske, editor. Conservation benefits of rangeland practices: assessment, recommendations, and knowledge gaps. United States Department of Agriculture, Natural Resources Conservation Service, Washington, D.C., USA.

Toledo, D., M. G. Sorice, and U. P. Kreuter. 2013. Social and ecological factors influencing attitudes toward the application of high-intensity prescribed burns to restore fire adapted grassland ecosystems. Ecology and Society 18(4):9. http://dx.doi. org/10.5751/ES-05820-180409

Toombs, T. P., J. D. Derner, D. J. Augustine, B. Krueger, and S. Gallagher. 2010. Managing for biodiversity and livestock: a scaledependent approach for promoting vegetation heterogeneity in western Great Plains grasslands. Rangelands 32(3):10-15. http:// dx.doi.org/10.2111/RANGELANDS-D-10-00006.1

Trainor, A. M., J. R. Walters, D. L. Urban, and A. Moody. 2013. Evaluating the effectiveness of a Safe Harbor Program for connecting wildlife populations. Animal Conservation 16 (6):610-620. http://dx.doi.org/10.1111/acv.12035

Twidwell, D., W. E. Rogers, S. D. Fuhlendorf, C. L. Wonkka, D. M. Engle, J. R. Weir, U. P. Kreuter, and C. A. Taylor Jr. 2013. The rising Great Plains fire campaign: citizens' response to woody plant encroachment. Frontiers in Ecology and Environment 11:e64e71. http://dx.doi.org/10.1890/130015

U.S. Census Bureau. 2016. Educational attainment in the United States: 2016. U.S. Census Bureau, Washington, D.C., USA. [online] URL: https://www.census.gov/data/tables/2016/demo/ education-attainment/cps-detailed-tables.html

U.S. Department of Agriculture (USDA). 2015. 2012 Census of agriculture highlights: cattle industry. USDA, Washington, D.C., USA.

Vallentine, J. F. 2001. Grazing management. Second edition. Academic, San Diego, California, USA.

Willcox, A. S., W. M. Giuliano, and M. C. Monroe. 2012. Predicting cattle rancher wildlife management activities: an application of the theory of planned behavior. Human Dimensions of Wildlife 17:159-173. http://dx.doi.org/10.1080/10871209.2012.639043

With, K. A., A. W. King, and W. E. Jensen. 2008. Remaining large grasslands may not be sufficient to prevent grassland bird declines. Biological Conservation 141:3152-3167. http://dx.doi.org/10.1016/ j.biocon.2008.09.025 
Ecology and Society 23(4): 45

Yung, L., and J. M. Belsky. 2007. Private property rights and community goods: negotiating landowner cooperation amid changing ownership on the Rocky Mountain Front. Society \& Natural Resources 20:689-703. http://dx.doi.org/10.1080/089419$\underline{20701216586}$ 